\title{
A múltból átívelő jövő
}

\section{Magyar (Jubileumi) Jövőkutatási Konferencia}

50 éves a magyar jövőkutatás, 2018

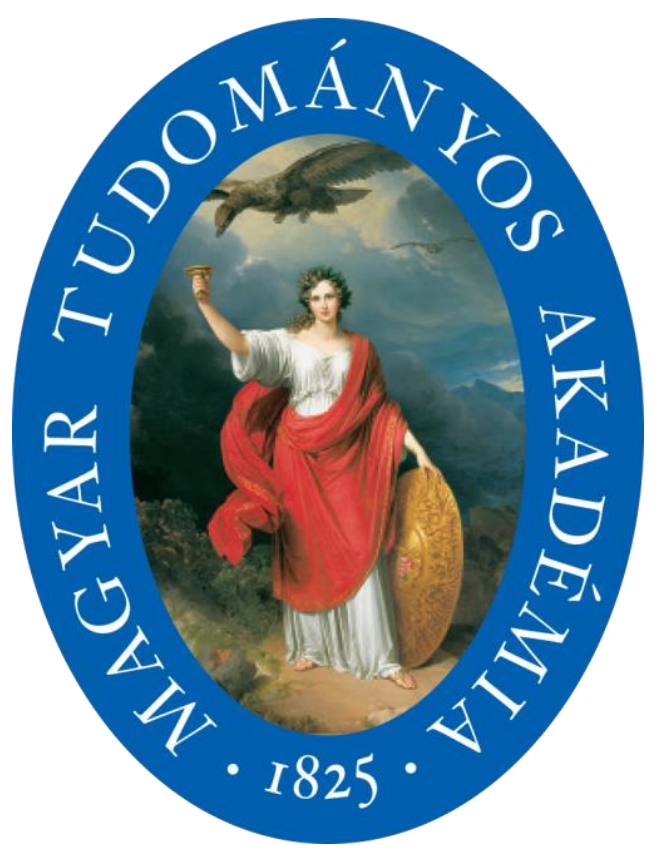

Budapest, 2018. november 14-15.

Konferenciakötet

\author{
Palatia \\ 2018
}




\section{Lektorok}

a Programtanács tagjai:

Besenyei Lajos

Hideg Éva

Nováky Erzsébet

Tóth Attiláné

Tóthné Szita Klára

\section{Szerkesztők}

Nováky Erzsébet

S. Gubik Andrea

(C) Szerzők, 2018

(C) Szerkesztők, 2018

(C) Kiadó, 2018

ISBN 978-615-5904-08-0

\section{Kiadó}

Palatia Kiadó és Nyomda 9026 Győr, Viza u. 4.

Telefon: +36-96/510-100

E-mail: info@palatia.hu

Készült 150 példányban 


\title{
Foresight as a governance tool to help shape the next production revolution
}

\author{
Attila Havas \\ kandidátus, tudományos főmunkatárs \\ MTA KRTK Közgazdaságtudományi Intézet \\ havas.attila@krtk.mta.hu \\ K. Matthias Weber \\ PhD, Head of Competence Unit, Innovation Systems \& Policy \\ Austrian Institute of Technology \\ matthias.weber@ait.ac.at
}

\begin{abstract}
INTRODUCTION ${ }^{1}$
Day-to-day decisions, guided by long-term, strategic thinking, tend to lead to more targeted - ideally also more favourable - outcomes than ad hoc decisions. Of various types of prospective analyses, this paper focuses on foresight because this is a particularly relevant approach to address the opportunities and challenges triggered by the next production revolution (NPR): besides facilitating debate and systemic thinking about possible futures, foresight also helps shape the future. A well-designed and conducted foresight process identifies and assesses in a systematic and transparent way those societal, technological, economic, environmental, and policy factors and trends that are likely to affect competitiveness, wealth creation and quality of life. Such analysis can be used by decision-makers as inputs for issue definition, as well as for designing new strategies and actual measures. It can help turn long-term concerns into urgent priorities. At the same time, foresight can raise awareness of such factors among the stakeholders involved in the process, mobilising them to act and preparing the ground for complementary actions and strategies. In this way, foresight can contribute to the emergence of more coherent expectations and strategies, making policy implementation more effective. By exploring multiple futures (as opposed to a single future) and by bringing together major stakeholders with diverse backgrounds, expectations and interests, foresight can help decision-
\end{abstract}

\footnotetext{
${ }^{1}$ This paper is a revised and abridged version of Havas and Weber (2017b).
} 
makers cope with an uncertain future and provide the foundations for more robust decision-making.

This is highly pertinent in the context of the next production revolution. The fast and interconnected changes in technologies, materials, processes and business models have major implications for the strategies of many different types of innovation and societal actor. There is a strong need for orchestration among these actors in order, for instance, to set standards for interoperability, security and privacy, or to develop appropriate curricula and education methods for skills development. These are just a few of the necessary actions to prepare for the future opportunities and challenges of the next production revolution.

The paper is organised as follows. Sections 2 and 3 briefly review the most important types of prospective analysis and their policy relevance in the context of the next production revolution. Then the potential benefits of foresight and its roles in shaping policies are discussed. The main conclusions are presented in section 5.

\section{FORESIGHT AND ITS POLICY RELEVANCE}

Prospective analyses can be conducted in various forms and pursue different purposes. The best-known forms include forecasting, critical (or key) technologies exercises, foresight, strategic planning in the private sector and indicative national planning in the public sector. Our analysis focuses on foresight, but to better understand its policy relevance - what can and cannot be expected from foresight it is worth briefly juxtaposing foresight with other types of prospective analysis. Two fundamentally different systematic approaches to the future are considered here: forecasting and foresight. Forecasters assume that the future is essentially determined by fairly stable structural and institutional settings, the main features of which can be called driving forces. The main task is thus to identify these driving forces, devise a reliable quantitative model, collect the relevant data and run simulations to generate future extrapolations at given points in time. Experts need to be involved in developing these future extrapolations, which may differ from each other quantitatively, but not structurally (that is, the same variables are used throughout, even if their values change from forecast to forecast). Forecasting can be used either for pure academic exercises or as a decision-preparatory tool both in the public and private sector.

Foresight processes, in contrast, are based on the assumption that the future can be shaped by deliberate present-day actions: at least some unfavourable trends can be altered (redirected, slowed down, or stopped altogether) to some extent and new, desirable ones can be set in motion as a result of private and public actions. Foresight, therefore, explores multiple, structurally different, futures. In uncertain times, thinking in terms of multiple futures is a necessary precondition for devising strategies to cope with unexpected developments.

To realise the potential of foresight to shape the future, major stakeholders need to be involved not only to identify, but also to assess, the major (current, emerging and future) trends, consider a set of feasible futures, and select the most favourable 
one, and prepare for less preferred ones. In this way, values and interests play a decisive role in foresight processes, and thus it is crucial to make the entire process inclusive and transparent. With the help of participatory methods, foresight can incorporate different perspectives when exploring possible futures and bring to the fore a range of relevant influences and impacts of the issues in question. The process itself can have systemic impacts: due to intense dialogue, existing networks of major actors are likely to be strengthened, new ones created, a future-oriented way of thinking reinforced. The novel, participatory methods also reshape the overall decision-making culture in the affected policy domain.

Furthermore, most foresight activities aim at achieving a common understanding of what a desirable future might be. Such visions and - associated with them - more operational roadmaps can be powerful instruments to assemble different key players around a shared agenda. The main benefit of such visions, roadmaps and strategic agendas is that they help reduce uncertainty about the ambitions of partners and competitors, and thus assist long-term decision-making. Moreover, once participants arrive at a shared vision, they can expect that most of their fellow participants will take steps to achieve that chosen future state, and thus align their future actions to the jointly identified favourable future.

Foresight needs to be clearly distinguished from the strategies it is supposed to feed. In the context of the next production revolution, the German Industrie 4.0 initiative may serve as an example of a strategy, which was inspired at least partly by prior foresight activities in Germany.

The next production revolution is likely to trigger complex changes given the interactions of new technologies (such as 3D printing and scanning, the Internet of Things, machine-to-machine (M2M) and person-to-machine (P2M) communications and interactions, and advanced robotics); new materials (in particular bio- and nanobased materials); new processes (for example, data-driven production, artificial intelligence and synthetic biology); as well as new business models (exploiting mass customisation, sharing and the platform economy, and servitisation of manufacturing) (OECD, 2017). These changes would affect research, technological development and innovation activities (direction of search, allocation of funds, commercialisation, ethical concerns); the labour market (via job creation and job destruction); income distribution and well-being; skill requirements (and thus formal training via the education system, retraining, life-long learning); and, several fields of regulation (for instance intellectual property rights (IPR), privacy, security and safety investment). Furthermore, digitalisation can be a major enabler of the circular economy (for instance, via mass customisation, smart logistics, smart cities, and smart homes). The policy implications of the next production revolution are so wideranging that it would be difficult to mention a major policy domain, which would be untouched by the sorts of sweeping changes noted above.

The need for policy orchestration is, therefore, rather strong. Foresight would assist policy-makers in identifying priorities for future STI policies, but it also allows 
dealing with several of the aforementioned complex changes. ${ }^{2}$ First, it would facilitate a systemic approach, consider multiple futures and draw on the diverse set of knowledge and experience of participants. Furthermore, a strong sense of ownership among participants could work as an additional factor to keep up the momentum of orchestrated policy design and implementation. Second, the next production revolution is likely to increase uncertainty. Yet, a shared vision, developed - and thus "owned" - by the major stakeholders participating in a foresight process, can reduce uncertainty. Third, the next production revolution is also likely to induce systemic changes, for instance, by facilitating the emergence of new innovation ecosystems or radically overhauled national, sectoral or regional innovation systems. A transformative foresight process, aimed at considering and assisting these systemic changes, can contribute to reshaping the prevailing power structures (which might constrain the desired changes) and reframing policy rationales, the overall decisionmaking culture and methods, and thus the efficacy and efficiency of policies.

\section{FOUR ARCHETYPES OF PROSPECTIVE ANALYSIS ADDRESSING NEXT PRODUCTION REVOLUTION ISSUES}

Prospective analyses can take many different forms, varying in their specific aims, thematic coverage, geographic scope, focus, methods and time horizons. They also vary in their breadth of thematic coverage (a focus on science and technology (S\&T) issues versus a broader focus on innovation and production systems) and their breadth of participation (confined to topic experts versus broader participation). Combining these distinctions, four different archetypes ${ }^{3}$ of prospective analysis can be identified (Table 1).

Countries have applied a multitude of approaches and methods to identify and prepare for the opportunities and challenges that are likely to be raised by the next production revolution. Given the interrelatedness of technologies, new materials and processes, and new business models relevant to the next production revolution, a systemic approach seems more appropriate to inform next production revolution policies than a narrower S\&T focus. Furthermore, participatory approaches enable various innovation and societal actors to bring together a much richer set of knowledge, experience, values, aspirations, perspectives and strategies to analyse the complex technological, economic, social, and potentially environmental changes that are expected. Yet, in certain cases, narrower expert-based projects have an important advantage: their results are normally produced more quickly and at a lower cost.

\footnotetext{
${ }^{2}$ Foresight can also assist decision-makers in the private sector at firm and sectoral level, for instance in tackling changes induced by the next production revolution in investment opportunities; co-ordinating technological, organisational, business model, financial, managerial and marketing innovations; as well as re-organising and co-ordinating international innovation and production networks.

${ }^{3}$ Archetypes are relevant for analytical purposes to support strategy-setting processes, but real life cases often 'sit' between them.
} 
Table 1 Four archetypes of prospective analyses, with selected examples

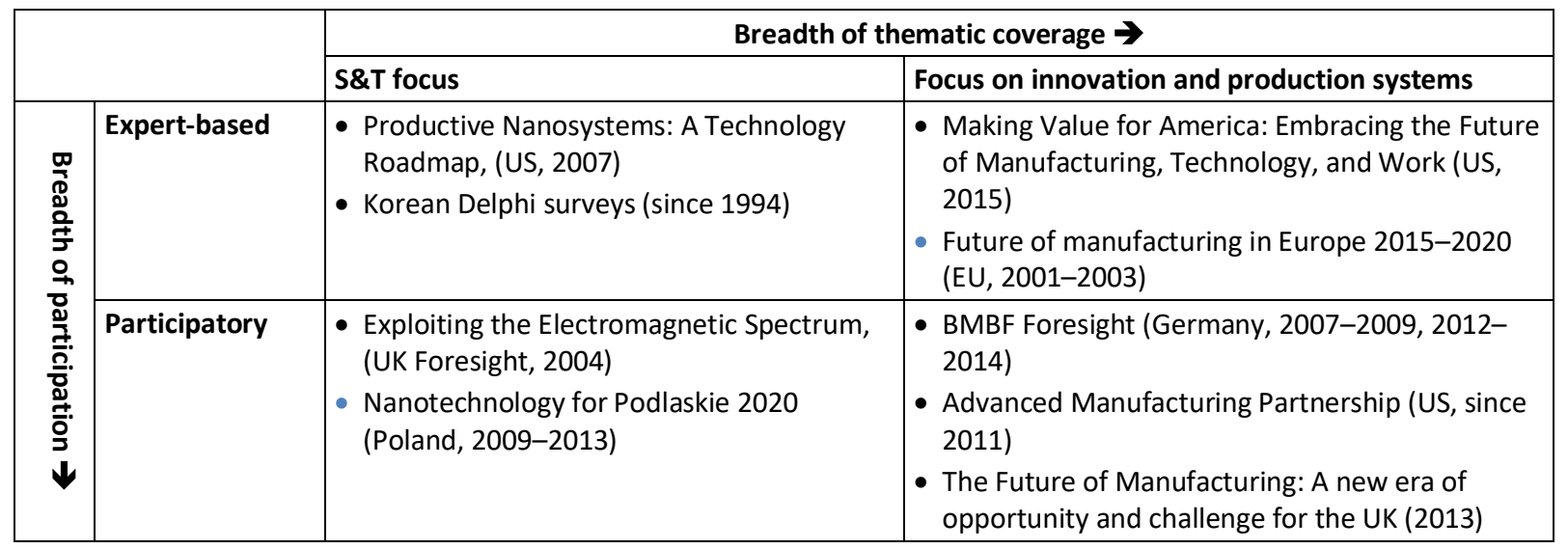

Source: authors' compilation

\section{POTENTIAL BENEFITS OF FORESIGHT AND ITS ROLES IN DEVISING POLICIES}

\section{Potential benefits of foresight}

Foresight can help decision makers cope with an uncertain future (Cassingena Harper, 2016; Havas et al., 2010). It can aid policy formation by generating reports that analyse the dynamics of change, future challenges and related options for action. Such analysis is used by policy-makers as input for issue definition, as well as for designing policies. This can provide the foundations for more robust policies, foster systems thinking, offer a new framing of policy issues, and turn long-term concerns into urgent policy priorities. Foresight can also play a role in making policy implementation more effective by facilitating the mobilisation and alignment of key stakeholders, and supporting policy co-ordination. In this way, foresight can supplement traditional top-down policy instruments, by shaping the mindsets of those participating in the process, and thus preparing the ground for complementary actions and strategies.

For these benefits to materialise, foresight needs to achieve impacts in different terms:

- in cognitive terms, to help prepare the mindsets of people for possible changes (new contexts, new socio-economic processes), which would require new ways of thinking;

- in procedural terms, by contributing to a change in decision-preparation processes, for instance, by including more, and a wider set of, stakeholders;

- in substantive terms, to actually change the content of policies;

- in terms of structural and/or organisational changes.

The benefits mentioned above correspond to the intended impacts of foresight, but it is far from certain that such intended impacts will actually be achieved. Intended impacts also need to be seen against the backdrop of the policy governance 
system in which the foresight process is embedded. In essence, a foresight process can either reinforce the existing system of policy governance or contribute to transforming it. In this way, the appropriate design of a foresight process is dependent on prior problem perception. In particular, the frame of reference is key, that is, how the problem area is delineated and whether the existing policy governance sub-system, or other parts of the innovation system, are to be reinforced or transformed.

In addition to the intended impacts, there can also be unintended impacts, which can be either positive or negative. Unintended impacts, by their very nature, can rarely be anticipated: they often arise from indirect and unknown pathways of influence. For instance, the changes in the mindset of policy-makers and other stakeholders, which a foresight activity have triggered, may help strengthening or building capabilities of strategic thinking that may be equally useful in other policy domains. The same can be said about new networks built and knowledge created.

The widely known problem of attribution arises when identifying and interpreting the impacts of foresight. Other factors than a given foresight process also affect policies, and foresight may well just reinforce and integrate isolated initiatives that have been around for a while. As a consequence, it is often difficult to observe and measure foresight impacts in a precise way. The problem of attribution is particularly pertinent in relation to far-reaching impacts, such as, for instance, on economic performance. The pathways of influence are multifaceted and indirect, with many other factors coming into play. The timing of expected impacts is also an important consideration, since while some effects may be almost immediate, others may take a long time to arise. ${ }^{4}$

Disentangling how impacts unfold is a challenging task (Georghiou and Keenan, 2006). In the foresight literature, it is often argued that the "process" benefits are (at least) as important for achieving impacts as the "products", that is, reports, lists of priorities, policy recommendations, roadmaps, etc. (Amanatidou and Guy, 2008). This is because the process is more likely than any report to change the mindsets of decision-makers and help structure new networks (without denying the influence of well-written reports and policy recommendations).$^{5}$

\section{Possible roles of foresight in shaping and implementing policies ${ }^{6}$}

\section{Providing the foundations for more robust policies}

Foresight explores different possible futures. In uncertain times, thinking in terms of multiple future states is a necessary precondition for devising policies to cope with unexpected developments. The Shell experience of the early 1970s is a well-known example: having considered an oil crisis as one of its possible futures, the company

\footnotetext{
${ }^{4}$ For a more detailed account on possible intermediate and ultimate impacts, see, e.g. Havas et al. (2010).

5 Process benefits can also occur in terms of improved decision-preparation processes, as well as more efficient structural and/or organisational set ups.

${ }^{6}$ Havas and Weber (2017b) illustrates these potential roles by actual foresight processes addressing NPR issues.
} 
was better prepared than its competitors to tackle this - until then an unthought-of situation once it occurred (Jefferson, 2012; Shell, 2013). Foresight can also make policies more robust by bringing together into policy dialogues participants with diverse backgrounds, in order to tap into their wide-ranging accumulated knowledge, complementary experiences, aspirations and ideas.

\section{Fostering systems thinking}

In a complex world, phenomena cannot be understood in an isolated manner, but must be seen in context, considering a range of different viewpoints. Foresight, on account of its participatory nature, and drawing on relevant methods, is a means to incorporate different perspectives when exploring possible futures and to bring to the fore a range of relevant influences on, and impacts of, the issue in question. The process itself can also have systemic impacts, with intense dialogues strengthening existing, or creating new, networks of major actors, and reinforcing a future-oriented way of thinking. The novel, participatory methods used in foresight can also reshape the overall culture of policy decision making, especially in the domains of education, industrial, and innovation policies.

\section{New framing of policy issues}

Government bodies tend to be organised along the lines of well-established, and rigidly demarcated, policy domains. In such an environment it is often difficult to find an appropriate place for cross-cutting research domains or new modes of delimiting them (e.g. shifting from S\&T-led to societal challenge-driven research and innovation projects). Foresight processes have the potential to change not only the framing of policy issues, but also to induce organisational innovations.

\section{Turning long-term concerns into urgent policy priorities}

Agenda setting is about deciding which policy issues deserve most attention. Priority issues need to be identified, selected in a justified manner, and specified. Whether or not a problem is moved onto the policy agenda is a matter of the perceived urgency of the issue, and of the perception that government action may be necessary to tackle it.

Foresight can play a beneficial role for agenda setting in several regards, by making transparent why a seemingly long-term issue may require immediate policy attention. First, by focusing debates on the long-term, it contributes to changing the perception of longer-term issues and allows turning them into urgent ones. In this way, foresight can be a means to make explicit why long-term issues need to be treated with urgency on today's policy agendas.

Second, and related to the long-term perspective inherent to foresight, novel future-oriented rationales to underpin and justify policy interventions can be developed in the context of foresight, providing arguments justifying government intervention. 
Finally, visions often play an important supporting role in making long-term issues more palpable, because they serve as sources of inspiration and orientation for prioritisation and underlying rationales. While they may have, in the first instance, an influence on the mindsets of individual policy-makers and stakeholders, they also provide novel and powerful ideas for the formulation of rationales to legitimise and justify priorities and scope for government intervention, and can thus strengthen the credibility of policy agendas.

\section{Facilitating the mobilisation and alignment of key stakeholders}

Besides exploring possible futures, most foresight activities also aim to achieve a common understanding of what a desirable future might be. Such visions and, associated to them, more operational roadmaps, can be powerful instruments to assemble different key players in a domain around a shared agenda. The main benefit of such visions, roadmaps and strategic agendas is that they help reduce uncertainty about the ambitions of partners and competitors, and thus assist making long-term investment decisions. Moreover, once participants arrive at a shared vision, they can expect that most of their fellow participants would take steps to achieve that chosen future state, and thus align their future actions to the jointly identified favourable future.

\section{Supporting policy co-ordination}

Foresight usually aims to identify future issues that often cut across established areas of policy interest. By way of involving participants from different policy domains that are likely to be affected by these novel developments, a futures dialogue can be initiated across the boundaries of these fields. This can be a dialogue that contributes to creating a shared perception of emerging challenges, and complementary, if not joint, strategies to address them. Policy co-ordination can be fostered both horizontally (i.e. across policy domains, or between the parliament and government) and vertically (i.e. between ministries and executive agencies).

\section{Transforming the policy governance and other sub-systems}

Besides shaping policies, informing, advising and implementing policies as discussed above, foresight can also play a role at a systemic level. Thus, it is worth digging one layer deeper by considering if a foresight process is aimed at strengthening an existing innovation system (or any of its major sub-system, including the policy governance sub-system) or on the contrary, at reconfiguring it. In other words, another major potential role of foresight in shaping the new production revolution is transforming the industrial and innovation policy governance sub-systems and other parts of an innovation system.

Foresight offers opportunities for reflexive learning in a given policy domain. As a result, participants might conclude that the prevailing perspectives on policy issues and/or the configuration of the policy governance sub-system may be inadequate to 
address the economic, societal or environmental challenges they are facing. They can also recognise that the predominant "silo-thinking" in government circles hinders the orchestration of various policy actions that need to be aligned to be capable of effectively tackling major issues.

These insights can lead to the reconfiguration of the policy governance subsystem, or to be more modest, initiate further reflections concerning the adequacy of the configuration of a current policy governance sub-system to address systemic issues (e.g. the emergence of new RTDI practices and the evolution of new innovation ecosystems, also characterised by new business models. ${ }^{7}$

\section{CONCLUDING REMARKS}

Foresight can influence innovation activities and hence economic performance through a web of direct and indirect impacts. Through its process benefits and products (e.g. reports, visions, recommendations, roadmaps) it is likely to shape policy making. However, given the complexity of the pathways of influence indicated by the sheer number and diversity of actors involved in a foresight process and subsequent policy formation - it would be a rather demanding task to establish a clear and direct link between an actual foresight process and its impacts on policies. It is further complicated by indirect impacts on innovation and economic activities and performance, structural changes, and ways of thinking and behaviour of the major actors of an innovation system.

Furthermore, the potential roles and expected impacts will vary by the type of prospective analyses. Participatory processes mobilise a wider set of knowledge, experience, aspirations and world views compared to an expert-based project. Hence, more novel and unconventional ideas can be expected, which can be better substantiated given the diversity of viewpoints, since ideas would be more thoroughly tested and contested from various angles. Furthermore, a deeper, more thorough understanding of major long-term challenges and their social, environmental and economic repercussions is more likely to stem from participatory processes. Policies, therefore, would be better substantiated and their credibility and legitimation strengthened. A wider set of policies could be more consciously orchestrated, increasing the effectiveness of their implementation.

Clearly, prospective analysis focusing on innovation and manufacturing systems would consider a broader set of issues than S\&T centred projects, with benefits for both policy preparation and implementation. Given the complex issues - interrelated technological, economic, societal and environmental opportunities and challenges brought about by the next production revolution, a systemic approach seems to be more appropriate as a foundation for devising policies aimed at tackling these farreaching and profound changes. Yet, in certain contexts, an S\&T centred prospective analysis can also be useful, but it should be clear from the outset that different and only more limited benefits and impacts can arise from this approach.

\footnotetext{
${ }^{7}$ Main features of various types of STI policy governance sub-systems and the conditions for a successful transformative foresight process are analysed in detail in Havas and Weber (2017), illustrated by actual cases.
} 


\section{REFERENCES}

Amanatidou, E., Guy, K. (2008). Interpreting foresight process impacts: Steps towards the development of a framework conceptualising the dynamics of 'foresight systems', Technological Forecasting and Social Change, 75 (4): 539-557

Cassingena Harper, J. (2016). The Impact of Technology Foresight on Innovation and Innovation Policy, in: Edler, J., Cunningham, P., Gök, A., Shapira, P. (eds), Handbook of Innovation Policy Impact, pp. 483-504, Cheltenham: Edward Elgar

Georghiou, L., Keenan, M. (2006). Evaluation of national foresight activities: Assessing rationale, process and impact, Technological Forecasting and Social Change, 73 (7): 761-777

Havas, A., Schartinger, D., Weber, M. (2010). The impact of foresight on innovation policy making: recent experiences and future perspectives, Research Evaluation, 19 (2): 91-104

Havas, A., Weber, K.M. (2017a). The 'fit' between forward-looking activities and the innovation policy governance sub-system: A framework to explore potential impacts, Technological Forecasting and Social Change, 115: 327-337

Havas, A., Weber, K.M. (2017b). The role of foresight in shaping the next production revolution, OECD: The Next Production Revolution: Implications for Governments and Business, pp. 299324, Paris: OECD Publishing

Jefferson, M. (2012). Shell scenarios: What really happened in the 1970s and what may be learned for current world prospects, Technological Forecasting and Social Change, 79 (1): 186-197

OECD (2017). The Next Production Revolution: Implications for Governments and Business, Paris: OECD Publishing

Shell (2013). 40 years of Shell scenarios, http://s05.static-shell.com/content/dam/shellnew/local/corporate/corporate/downloads/pdf/shell-scenarios-40yearsbook080213.pdf 